\title{
Study on Thermal Shock Resistance of Plasma Sprayed $\mathrm{ZrO} 2$ Coating
}

\author{
Yuan Donglin, Li Wenge, Zhao Yuantao
}

\begin{abstract}
In this paper, the research progress of thermal shock resistance of zirconia ceramic materials is summarized, and the effects of different stabilizers on the thermal shock resistance of zirconia ceramic materials are briefly described. Through research, it is found that when adding cerium oxide with a mass fraction of $5.5 \%$ in the zirconia ceramic coating, the thermal expansion property of the coating can be minimized to improve the thermal shock resistance of the coating.; A $25 \%$ mass fraction of $\mathrm{CeO} 2$ is dissolved in the nano-yttria partially stabilized zirconia coating to form a stable tetragonal phase compound, which improves the thermal shock resistance of the coating.; adding a mass fraction of $3.0 \% \mathrm{SiO2}$ to the zirconia ceramic coating, the coating produces uniform pores, The modulus of elasticity and the stresses received are minimal, making the coating best resistant to thermal shock.
\end{abstract}

Index Terms - high temperature coating; ceramic material; stabilizer; thermal shock resistance

\section{INTRODUCTION}

With the rapid development of aerospace and marine shipbuilding, the application environment conditions of aerospace and marine ship engines will become more and more severe. The hot end components (turbine discs, turbine blades, combustion chambers, etc.) on the aero engine are one of them. The working temperature of the hot end components is as high as $1400{ }^{\circ} \mathrm{C}$ or higher, which exceeds the normal working limit temperature of the high temperature nickel base alloy by about $350^{\circ} \mathrm{C}^{[1]}$. Ceramic materials have excellent properties such as high temperature resistance, wear resistance and corrosion resistance. They are ideal high temperature structural materials and are widely used in high temperature engineering. However, due to their brittleness and poor thermal shock resistance, their applications are limited. Thermal shock resistance refers to the ability of a material to withstand rapid changes in temperature without being destroyed. In the environment of temperature change(thermal shock), the strength of structural ceramic materials will be greatly reduced, and peeling or even brittleness will

use.

Therefore, to study the effect of thermal shock resistance on the properties of high temperature structural ceramic materials, and to explore ways to improve the thermal shock resistance is a problem to be solved. In this paper, the research progress of thermal shock resistance of zirconia ceramic

Yuan Donglin Merchant Marine academy \& Naval Architecture and Ocean Engineering,Shanghai Maritime University, Shanghai Lingang new city 21306 , China

Li Wenge Merchant Marine academy,Shanghai Maritime University ,Shanghai Lingang new city 201306,.China

Zhao Yuantao Merchant Marine academy,Shanghai Maritime University ,Shanghai Lingang new city.201306,.China materials is summarized. The main factors affecting the thermal shock resistance of zirconia ceramic materials are briefly described, and the future development direction of zirconia ceramic materials' thermal resistance is pointed out.

\section{RESEARCH STATUS AT HOME AND ABROAD}

After decades of research, the composition and structure of high temperature resistant coating materials have been greatly improved. According to the selection of components and the optimization of structure, the development research experience of high temperature resistant coatings can be simply divided into the following periods:

In the $1960 \mathrm{~s}$, the $\beta_{2} \mathrm{NiAI}$-based aluminide coating was successfully developed However, the $1 \mathrm{NiA} 1$ phase is brittle and easily cracked, and the $\mathrm{Al}$ atoms diffuse rapidly toward the substrate in a high temperature environment, resulting in a short coating life. ${ }^{[2 \sim 3]}$.

In the $1970 \mathrm{~s}$, improved aluminide coatings, such as $\mathrm{A}_{12} \mathrm{Cr}$, $\mathrm{A}_{12} \mathrm{Si}, \mathrm{A}_{12} \mathrm{Ti}$, and $\mathrm{Pt}_{2} \mathrm{~A} 1$, were introduced. Among them, the platinum-aluminum compound coating formed by Pt-plated $\mathrm{Al}$ has a longer service life and became popular. Hot spots, there are still relevant research reports.

In the 1980s, a plasma sprayed MCrAIY coating that could adjust the coating composition and provide high temperature oxidation resistance at higher temperatures was developed. This is also the most common metal bonding layer they have used in TBCs. It overcomes the weakness of the traditional aluminide coating and the matrix, and has a significant improvement in resistance to high temperature oxidation.

Ceramic thermal barrier coatings $\left(7 \% \quad \mathrm{Y}_{2} \mathrm{O}_{3}\right.$ partially stabilized $\mathrm{ZrO}_{2}$ coated TBCs), which have been widely studied and used since the late 1980s, have significant thermal insulation effects and are stable in high temperature environments, showing great advantages ${ }^{[4 \sim 5]}$

\section{A. Research status of Zirconium Oxide ceramics}

Zirconium dioxide series coating is one of the most widely used high temperature resistant ceramic coatings. It has high temperature insulation performance, stable phase at high temperature, erosion resistance, and is not easily wetted by liquid metal. Since its inception in the early 1970s, it has been widely used in high temperature working parts such as gas turbine hot end parts and turbine blades. About $300 \mathrm{t} \mathrm{ZrO}_{2}$ is used annually on high temperature ceramic coatings (2003), and thermal barrier coatings will reach an annual growth rate of $12 \%$ in the next 10 years, with an annual growth rate of $25 \%$ in engine components has broad application development prospects. Many researchers have conducted in-depth research on the thermal shock resistance and high temperature oxidation resistance of $\mathrm{ZrO}_{2}$ series coatings in atmospheric high temperature environment ${ }^{[6 \sim 8]}$.

The first ceramic layer material used for TBCs was $\mathrm{MgO}$ or 
$\mathrm{CaO}$ fully stabilized $\mathrm{ZrO}_{2}$ (MSZ or CSZ), but it was later found that due to the higher vapor pressure of $\mathrm{MgO}$ or $\mathrm{CaO}$, it is easy to cause loss due to high arc temperature during spraying. The stability of $\mathrm{ZrO}_{2}-\mathrm{CaO}$ is impaired. During the thermal cycle cooling process, $\mathrm{MgO}$ or $\mathrm{CaO}$ will be dispersed from the solid solution, which not only affects the stabilization effect of $\mathrm{ZrO}_{2}$, but also increases the thermal conductivity of the coating material, thereby reducing the thermal insulation performance of the thermal barrier coating. Coating in order to improve the thermal cycle of life, and now part stabilizer instead of $\mathrm{Y}_{2} \mathrm{O}_{3}$ gradually stable $\mathrm{ZrO}_{2}$ (YSZ), stability of $\mathrm{ZrO}_{2}$ coatings with $\mathrm{Y}_{2} \mathrm{O}_{3}$ part, to a certain extent to avoid the stability of $\mathrm{CaO}$ and $\mathrm{MgO}$ style stabilizers of $\mathrm{ZrO}_{2}$ loss problem, can make the system of high temperature and low temperature to maintain stable phase state, thus has good stability At present, YSZ is the most widely used material in thermal barrier coatings. It has a low thermal conductivity (4.2W / mk) and a high thermal expansion coefficient $\left(10.7 \times 10^{-6} /{ }^{\circ} \mathrm{C}^{-1}\right)^{[9 \sim 10]}$ high melting point. High temperature phase stability, good corrosion resistance and high thermal cycle life.

\section{B. Theoretical study on thermal shock resistance of ceramic materials}

Thermal shock resistance refers to the ability of materials to withstand temperature fusion, and is a comprehensive response of mechanical properties and thermal properties to heated conditions [11]. Thermal shock damage of ceramic materials can be divided into two types: instantaneous fracture under thermal shock and cracking, spalling, and overall damage under thermal shock cycle. Due to the different thermal shock damage modes of ceramic materials, there are two kinds of thermal shock evaluation theories widely used: one is the critical stress fracture theory based on elastic mechanics, and the other is thermal shock damage based on fracture mechanics. ${ }^{[12 \sim 13]}$. Thermal shock fracture refers to the instantaneous fracture of a material caused by the inherent strength of the material to resist thermal stress caused by thermal shock temperature. Thermal shock damage of materials refers to the thermal damage process of cracking and spalling of materials until bursting or overall fracture under thermal shock stress ${ }^{[14 \sim 16] .}$.

\section{EFFECT OF DIFFERENT STABILIZERS ON THERMAL SHOCK RESISTANCE OF $\mathrm{ZRO}_{2}$}

Pure $\mathrm{ZrO}_{2}$ generally has three crystal structures ${ }^{[17]}$, namely, a monoclinic phase ( $\mathrm{m}$ phase), a tetragonal phase ( $\mathrm{t}$ phase) and a cubic phase (c phase). The phase transition temperature is as follows (if there is other oxide doping in $\mathrm{ZrO}_{2}$, the phase transition temperature is generally lower).

$$
\text { Monoclinic phase } \underset{950^{\circ} \mathrm{C}}{\stackrel{1150^{\circ} \mathrm{C}}{\longrightarrow}} \text { Tetragonal phase } \stackrel{2370^{\circ} \mathrm{C}}{\longrightarrow} \text { Cubic phase }
$$

Figure 1. Schematic diagram of temperature conversion of $\mathrm{ZrO}_{2}$ phase

In the process of heating and cooling, $\mathrm{ZrO}_{2}$ ceramics will undergo a high-temperature t-phase to $\mathrm{m}$-phase transition, and a phase change stress will occur with a $3-5 \%$ volume change. In the case of thermal cycling, when such a phase change occurs, The phase transformation stress will cause cracks and spalling of the ceramic layer during thermal shock ${ }^{[18-19]}$, which will invalidate the coating. In order for the thermal barrier coating to work under the thermal cycling conditions near the phase transition temperature and extend the service life of the coating, it is necessary to reduce the occurrence of such phase transitions and maintain $\mathrm{ZrO}_{2}$ as cubic or square phase at high temperatures. In order to prevent the conversion of $\mathrm{ZrO}_{2}$ from tetragonal $\mathrm{ZrO}_{2}$ to monoclastic $\mathrm{ZrO}_{2}$, oxides such as yttrium oxide $\left(\mathrm{Y}_{2} \mathrm{O}_{3}\right)$, calcium oxide $(\mathrm{CaO})$, magnesium oxide $(\mathrm{MgO})$ and oxidation decoration $(\mathrm{CeO} 2)$ were used as tetragonal stabilizers and dissolved into $\mathrm{ZrO}_{2}$.

It has been found through research that adding a small amount of oxides such as $\mathrm{MgO}, \mathrm{CaO}, \mathrm{Y}_{2} \mathrm{O}_{3}$ or $\mathrm{CeO}_{2}$ to $\mathrm{ZrO}_{2}$ can stabilize or partially stabilize $\mathrm{ZrO}_{2}$ to a certain extent. Different stabilizers have different phase stabilization effects, and the respective stabilization mechanisms may also be different.

\section{A. Effect of $\mathrm{Y}_{2} \mathrm{O}_{3}$ on Thermal Shock Resistance of Zrconia Ceramics}

Different mass fractions of cerium oxide were added to zirconia, and sintered at a pressure of $1460^{\circ} \mathrm{C}$ for $4 \mathrm{~h}$ to obtain yttria-stabilized zirconia ceramics ${ }^{[20] .}$

For the study of thermal shock resistance of brittle ceramic materials ${ }^{[21 \sim 23]}$, the theory of thermoelasticity is generally adopted. This theory refers to the balance between thermal stress and the strength of the material itself as the reference. The smaller the thermal stress, the strength of the material itself .The more balanced, the better the thermal shock resistance of the material ${ }^{[24]}$

Thermal stress formula:

$$
\sigma_{\mathrm{h}}=E \cdot \alpha \cdot \Delta \mathrm{T} /(1-v)
$$

In the formula:

$$
\begin{aligned}
& \mathrm{E}-\text { Young's modulus of elasticity } \\
& \alpha-\text { Thermal expansion coefficient } \\
& \quad \Delta \mathrm{T}-\mathrm{Thermal} \text { shock temperature difference } \\
& v-\text { Poisson's ratio }
\end{aligned}
$$

The smaller the modulus of elasticity, the coefficient of thermal expansion and the Poisson's ratio, the smaller the thermal stress of the material and the higher the strength of the material. Therefore, the better the balance between the thermal stress and the strength of the material itself, the better the thermal shock resistance of the material.

The high-purity $\mathrm{Y}_{2} \mathrm{O}_{3}$ powder (purity $\geqslant 99.99 \%$ is completely dissolved by concentrated nitric acid $(68 \%)$, the $\mathrm{Y}\left(\mathrm{NO}_{3}\right) \mathrm{s}$ solution is diluted, and the diluted solution is mixed with $\mathrm{ZrOCl}_{2}$ aqueous solution, and prepared by chemical coprecipitation method ${ }^{[25]}$,Different mass fractions of $\mathrm{Y}_{2} \mathrm{O}_{3-}$ $\mathrm{ZrO}_{2}$ powder. The prepared powder was subjected to high temperature calcination at $1100{ }^{\circ} \mathrm{C}$. After the powder was dry-formed, it was pressed and formed by cold isostatic pressing of $180 \mathrm{MPa}$. Finally, the sample was placed in an electric furnace at $1460{ }^{\circ} \mathrm{C}$ for normal pressure sintering, heat-sealed for $4 \mathrm{~h}$, and finally cooled with the furnace. The linear expansion coefficient of the zirconia ceramic material was measured by a PLY high temperature horizontal expander. A curve between the average linear expansion coefficient of the material and the cerium oxide content, As the thermal expansion device continues to heat up, the coefficient of expansion of the material first rises rapidly and then gradually becomes flat until it becomes substantially constant. 
By adding cerium oxide to the zirconia ceramic, the densification degree, hardness, and bending strength of the material can be improved. $\mathrm{Y}_{2} \mathrm{O}_{3}$ forms a displacement solid solution with $\mathrm{ZrO}_{2}$, which makes the material more dense $\mathrm{Wu}$ Shan and other research found that ${ }^{[26]}$ when the mass percentage reached $5.5 \%$, the densification degree of the material reached the highest, and the material properties here also obtained the maximum. When the mass percentage of cerium oxide reaches $5.5 \%$, the thermal expansion property of the material is the smallest, and the strength of the material itself is high, so the zirconia ceramic material obtained at this content has better thermal shock resistance.

\section{B. Effect of $\mathrm{CeO}_{2}$ on the seismic behavior of nano-zirconia ceramics}

The cubic phase is not present in the nano- $\mathrm{ZrO}_{2}$ coating obtained by plasma spraying. The nano-granulated powder is more fully melted during the spraying process, and is either stabilized into a non-transformed tetragonal phase or converted into a low-temperature monoclinic phase during the cooling process. The cubic phase exists in the micron $\mathrm{ZrO}_{2}$ coating, and the micron powder is not sufficiently melted during the spraying process, and there is a residual cubic phase. Because the nano $\mathrm{ZrO}_{2}$ coating is finer than the micron $\mathrm{YSZ}-\mathrm{ZrO}_{2}$ coating, the porosity is lower, the spreadability is better, the thermal shock resistance is better than that of the micron $\mathrm{ZrO}_{2}$ coating, and the antioxidant protection of the matrix is better. Therefore, researchers have also tended to study nano-zirconia ceramics in recent years ${ }^{[27 ~ 28]}$.

Wang Dongsheng et al. ${ }^{[2]}$ used atmospheric plasma spraying technology to prepare two thermal barrier coatings on the surface of high temperature alloy steel using conventional nano yttria partially stabilized zirconia (YSZ) and $25 \mathrm{wt} \%$ $\mathrm{CeO}_{2}$ (hereinafter referred to as CSZ) in YSZ. The two coatings were subjected to thermal shock tests at $900^{\circ} \mathrm{C}$, and the thermal shock resistance of YSZ and CSZ ceramic coatings was analyzed using SEM and EDS techniques It was found that when the YSZ thermal shock test was carried out 21 times, cracks appeared at the edge of the coating. When the test was carried out 30 times, the coating peeled off at the crack. The CSZ coating showed its first peel off at the edge of the coating only when the test was carried out 63 times. CSZ failed in the 63rd heat cycle, while YSZ failed in the $21 \mathrm{st}$. The thermal shock resistance of the new CSZ coating was significantly better than YSZ. $\mathrm{CeO}_{2}$ can improve the thermal shock resistance of $\mathrm{Y}_{2} \mathrm{O}_{3}$ partially stabilized $\mathrm{ZrO}_{2}$.

Theoretically, the difference between the thermal expansion coefficients of CSZ and YSZ and the bonding layer material is about (5-6) $\times 10^{-6}{ }^{\circ} \mathrm{C}^{-1}$ and $(6-7) \times 10^{-6}{ }^{\circ} \mathrm{C}^{-1}$, respectively. The smaller the difference between the thermal expansion coefficients, the higher the material matching ratio, the better the bonding strength between the two. The analysis shows that the CSZ coating bonding strength is better than YSZ, and the CSZ coating is X-ray diffraction before the thermal shock test. According to the analysis, the thermal shock resistance of CSZ coating is stronger than that of YSZ, which indicates that the addition of $\mathrm{CeO}_{2}$ to solid solution into YSZ forms a stable tetragonal phase compound, which improves the thermal shock resistance of the coating and prolongs the service life of the coating.

\section{Effect of Silicon Oxide on Thermal Shock Resistance of Zirconia Ceramics}

In the $\mathrm{ZrO}_{2}, \mathrm{SiO}_{2}$ particles are added, and during the spraying process, the $\mathrm{SiO}_{2}$ particles are spread on the surface of the substrate to form a flake or a coating in the form of fine particles, and then the molten ZYO particles are collided to re-melt or vaporize the $\mathrm{SiO}_{2}$. However, at this time, the ZYO has been spread, so that the vaporized $\mathrm{SiO}_{2}$ cannot escape, and the pores are formed in the coating. Eking et al. given that the relationship between elastic modulus and porosity ${ }^{[30]}$

$$
E=E_{0}\left(1-1.9 P+0.9 P^{2}\right)
$$

In the formula:

$E_{0}$ - Elastic modulus of the coating at a porosity of zero

$P$ - Coating porosity

$E$ - Elastic modulus of the coating when the porosity is $P$

During the thermal shock process, the thermal stress of the coating is proportional to the elastic modulus of the coating. The residual stress and thermal stress affect the coating at the same time, eventually leading to coating failure. The addition of $\mathrm{SiO}_{2}$ changes the porosity of the coating, resulting in a change in the modulus of elasticity of the coating, which further causes residual stresses after coating spraying and changes in thermal stress generated during thermal shock. According to thermodynamics, the thermal shock resistance of the coating is best when the porosity in the coating is $10 \%-15 \%{ }^{[31-32]}$ At the same time, the pore diameter and distribution in the coating have a significant effect on the thermal shock resistance of the coating. Only uniform distribution, pores with a diameter below $1 \mu \mathrm{m}$ are beneficial to improve the thermal shock resistance of the coating, and unevenly distributed coarse atmospheric pores. will reduce the thermal shock resistance of the coating.

Tang jiancheng et al. ${ }^{[33]}$ found that when $3.0 \% \mathrm{SiO}_{2}$ was added to the coating, the number of thermal shock crack initiation and thermal shock failure of the coating reached the maximum value, which increased from 32 and 46 times without $\mathrm{SiO}_{2}$ coating to 83 and 112 times respectively. When excessive $\mathrm{SiO}_{2}$ is added, the thermal shock resistance of the coating will be reduced. The addition of $\mathrm{SiO}_{2}$ will promote the formation of pores in the coating, and the porosity and diameter of pores increase with the addition of $\mathrm{SiO}_{2}$. The average diameter of pores in the coating of $\mathrm{SiO}_{2}$ is about 1 micron, the porosity is about $10 \%$, and the distribution of pores is uniform, so the elastic modulus and stress of the coating are the minimum, and the thermal shock resistance of the coating is the best.

\section{Other factors affecting thermal shock resistance of $\mathrm{ZrO}_{2}$ ceramics}

In addition to adding a small amount of stabilizers such as $\mathrm{MgO} 、 \mathrm{CaO} 、 \mathrm{Y}_{2} \mathrm{O}_{3}$ or $\mathrm{CeO}_{2}$ into $\mathrm{ZrO}_{2}$, other factors affect the thermal shock resistance of $\mathrm{ZrO}_{2}$ ceramics. For example, the effects of bonding layer and heat treatment on the thermal shock resistance of $\mathrm{ZrO}_{2}$ ceramics also have a certain degree of influence.

1) Effect of NiCrAIY bonding layer on thermal shock resistance of $\mathrm{ZrO}_{2}$ ceramics. NiCrAIY is the thermal 
expansion coefficient of the bonding layer between the metal matrix and $\mathrm{ZrO}_{2}$. During the thermal shock process, the thermal expansion coefficient of the interlayer material changes from the substrate to the bonding layer and the $\mathrm{ZrO}_{2}$ surface layer, which reduces the difference in thermal expansion. It avoids the detachment and failure of interlayer materials caused by thermal shock and exhibits the best thermal shock resistance.

2) Influence of heat treatment on thermal shock resistance of $\mathrm{ZrO}_{2}$ ceramics. The samples of magnesium oxide partially stabilized zirconia without heat treatment have lower thermal expansion coefficient and smaller volume contraction, so the thermal stress generated by volume change is reduced, which greatly improves the thermal shock resistance of the material.

\section{FUTURE PROSPECTS}

Modern ceramic materials have excellent properties such as high strength, high hardness, high temperature resistance, chemical corrosion resistance, wear resistance, oxidation resistance and thermal expansion. They have played an important role in aerospace, energy, machinery, automotive, chemical, metallurgical and other fields. But at the same time, the brittleness of materials is too great to withstand severe thermal shock, that is, its poor thermal shock resistance, which restricts the wider application and industrialization of structural ceramics in engineering.

Therefore, the study of thermal shock resistance of ceramic materials has been one of the main research directions in the field of high temperature structural ceramics.

\section{SUMMARY}

The thermal shock resistance of materials is closely related to the physical properties of materials. Although the physical properties of the selected material have been determined, according to the specific characteristics of the selected material, the elastic modulus and thermal expansion coefficient of the material can be reduced through optimization of the process to improve the thermal shock resistance of the material:

1) By adding yttrium oxide to zirconia ceramics, the densification degree, hardness and bending strength of the materials can be improved. $\mathrm{Y}_{2} \mathrm{O}_{3}$ and $\mathrm{ZrO}_{2}$ form substitutable solid solution, which makes the material denser. When the mass percentage reaches $5.5 \%$, the densification degree of the material reaches the highest, which also maximizes the properties of the material. When the yttrium oxide mass percentage reaches $5.5 \%$, the thermal expansion property of the material is the minimum, and the material's own strength is higher, so the zirconia ceramic material with this content has better thermal shock resistance.

2) By adding $25 \% \mathrm{CeO}_{2}$ solid solution to nano-yttrium oxide nano-stabilized zirconia coating in nano-zirconia ceramics, stable tetragonal phase compounds are formed to improve thermal shock resistance of the coating.

3) By adding $3.0 \% \mathrm{SiO}_{2}$ in the zirconia ceramic coating, the coating will produce uniform pores, minimize the elastic modulus and stress, and make the coating have the best thermal shock resistance.

4) The choice of bonding layer and the effect of heat treatment also have a certain impact on the thermal shock resistance of $\mathrm{ZrO}_{2}$ ceramics.
Because the research of thermal shock resistance of zirconia ceramics is not deep, the evaluation theory of thermal shock resistance also has fundamental defects. So there is still a lot of work to be done to improve the thermal shock resistance of zirconia materials.

\section{REFERENCES}

[1] Tang Zhongjie, Guo Tieming, Fu Ying, Hui Zhi, Han Changsong. Research Status and Development Prospect of Nickel-Based Superalloys[J]. Metal world 2014(01):36-40.

[2]Yang Wenhui, Zhai Rende. Effect of heat treatment temperature on microstructure and interdiffusion of thermal barrier coatings[J]. Equipment Environmental Engineering, 2019, 16(01): 7-12.

[3]Xu Huibin, Gong Shengkai, Liu Fushun. Research on Thermal Barrier Coating Material System of Aeroengine [J].. Journal of Aeronautics, 2000, 21(1): 7-12.

[4]Fan Ximei, Lin Jieqiong, Du Xianchang. Research Status of Ceramic Thermal Barrier Coatings[J]. Journal of Changchun University of Technology, 2003, 24(1): 65-67.

[5]Yang Hongbo, Liu Zhaohui, Yi Tongbin, Liu Na, Shu Xin, Luo Ping.Performance of $\mathrm{Al}_{2} \mathrm{O}_{3} / \mathrm{ZrO}_{2}$ Composite Structure Thermal Barrier Coating Prepared by Plasma Spraying[J].Materials For Mechanical Engineering,2017,41(11):63-67 +72.

[6] Zhang Yujuan, Zhang Yuchi, Sun Xiaofeng, et al. Development Status of Thermal Barrier Coatings. Material Protection [J]. Material Protection, 2004, 37(6): 26-27.

[7]S.Uwe,L.Christoph, EKlaus. Some recnt trends in research and technology of advanced thermal barrier coatings. Aerospace Sci Techn, 2003, 7:73

[8] Deng Shijun. High performance ceramic coating [J].. Beijing: Chemical Industry Press, 2004, 83-91: 223-229.

[9]Yin Yuchuan. Preparation and properties of liquid plasma sprayed $\mathrm{ZrO}_{2}$ based thermal barrier coatings [D]. Inner Mongolia University of Technology, 2017.

[10]Shan Chunyan,Chen Lizhang,Shan Yixin. Study on Wear Resistance of Plasma Sprayed $\mathrm{Al}_{2} \mathrm{O}_{3} / \mathrm{ZrO}_{2}$ Coating[J].New Technology \& New Process, 2016(02):93-95.

[11] Zhu Langtao, Yang Jun, Zhou Yiping, Yu Jia, Huang Fei Microstructure and Thermal Shock Resistance of $\mathrm{ZrO}_{2}-\mathrm{MoSi}_{2}$ Composite Coating for Plasma Spraying Crystallizer[J].Journal of Materials Protection,2016,49(01):15-18+6-7.

[12]Chen Haitao. Preparation of ZTA composite ceramics and its thermal shock resistance [D]. Zhengzhou University, 2018.

[13]Song Shixue, Ai Xing, Huang Fax. Research Progress in Thermal Shock Resistance and Mechanism of Structural Ceramics[J].. Journal of Ceramics, 2002, 23(4): 27- 31.

[14]WANG Jidong, WANG Zhihui, FENG Meng.Study on thermal shock r esi-stance of plasma sprayed $\mathrm{ZrO}_{2}$ thermal barrier coatings[J].Welding ,2009(11):31-34+70

[15] Zhai Wenfeng, Zhang Hongsong, Wang Fuxi, Li Shuhua, Ma Zhuang. Thermal Shock Resistance of Plasma Sprayed $\mathrm{ZrO}_{2}$ Thermal Barrier Coatings[J].Journal of Materials Protection,2007(04):4-6+73.

[16]Chu Kai,Wang Yan,Lu Xinjiang.Study on Thermal Shock Properties of Plasma Sprayed Nano $\mathrm{ZrO}_{2}$ Ceramic Coatings[J].Hot Working Technology,2006(06):53-55.

[17]Kingery W D. Metal- ceramic interaction: IV , absolute measurement of metal ceramic interfacial energy and interfacial adsorp-tion of silicon from ironsilicon alloys,J. Am.Ceram. Soc.2004,37:25- 42.

[18] Hasselman D P H. Elastic energy at fracture and surface energyas design criteria for thermal shock $[\mathrm{J}]$. J. Am. Ceram. Soc. 2003,46(11):535- 540.

[19] Hasselman D P H. Giffith criterion of thermal shock resistance of singl e- phase versus multiphase brittle ceramics,J. AM.Ceram.Soc.,2001,5 2:288-289

[20]Zhou Hong, Li Fei, He Bo, et al. Research progress of thermal barrier coating materials [J]..Materials Report, 2006, 20(10): 40-43

[21]Zhou Zehua, Ding Peida, Chen Wei, et al. Comprehensive analysis of mechanical and thermal properties of zirconia $[\mathrm{J}]$. Journal of Chongqing University: Natural Science Edition, 200225 (2): 60-62.

[22] Sun Zhanbo, Liang Gongying, Metal Rubbing Materials and Microstructure and Properties [J]. Xi'an Jiaotong University Press, 2010: 230-237.

[23] Lu Yanhong, Wang Quansheng, Wu Zijian Nano $\mathrm{ZrO}_{2}$, Thermal Shock Resistance Study of Thermal Barrier Coatings [J] Material Protection, 2006, 39(7): 9-11. 
[24] Gong Wenbiao, Li Yupeng, Liu Wei, et al. Preparation and high temperature performance of $\mathrm{CeO}_{2} / \mathrm{ZrO}_{2} \mathrm{YZO}$ nanostructured thermal barrier coatings. Journal of Inorganic Materials, 2010, 25(8): 860-864.

[25]Hu T, Michael Z C. Nanocrystallization and phase transformation inna nodispersed ultrafine zirconia particles from various homogeneous pre cipitation methods. J A Ceram Soc, 2003, 82 (9) : 2313-2320.3.

[26] Wu Shan, Jiang Xingzhen, Huang Zhibing, Jiang Quqing. Effect of Oxidation Recall Content on Mechanical Properties and Thermal Shock Resistance of Zirconia Ceramics [J] Guangzhou Chemical Industry, 2013, 41(12): 66-68.

[27] Elsing R, in plasm. 425. Knntek Balting U. Calculation of residual thermal stress coating [J] . SurF Coat Tech, 2000, 43/44: 416.

[28] Wen Yuan, Huang Huining, Zhang Guotao, Huang Xinchen, Yang Jingqi, Dai Yonggang. Research progress on thermal shock resistance of ceramic materials [J]. Foshan Ceramics, 2018, 28 (12): 1-7.

[29]Wang Dongsheng, Tian Zongjun, Wang Songlin, Shen Lida, Huang Yinhui.Regular and Nano $\mathrm{ZrO}_{2}-7 \% \quad \mathrm{Y}_{2} \mathrm{O}_{3}$ Plasma Sprayed Thermal Barrier and Its Thermal Shock Resistance after Laser Remelting[J].Journal of Materials Protection,2012,45(05): $54-56+68+87$.

[30]Feng Yajun, Wang Xingqing. Effect of $\mathrm{Y}_{2} \mathrm{O}_{3}$ on Microstructure and Properties of Zirconia,Ceramics[J].Journal of,Shanghai University(Natural Science), 2018,24(01):56-65.

[31] Xue Zongwei, Wu Feng, Li Zhijian, Li Xinwei, Yan Xu, Luo Xudong. Effect of composite additives on thermal shock resistance of magnesia ceramics[J]. Journal of Synthetic Crystals, 2018, 47(09): 1933-1937

[32]Shi Qingyun. Preparation and properties of high temperature phase stabilized zirconia powder and thermal barrier coating [D]. Hunan University, 2018.

[33] Tang Jiancheng, Shao Dechun, Guo Weihuan. Thermal Shock Resistance of Plasma Sprayed $\mathrm{SiO}_{2}+\mathrm{ZrO}_{2}$ Coatings[J]. Journal of Central South University of Technology 2001,32(01):63-65 